\title{
Ciudadanía, democracia y Estado en plena transformación
}

Este comentario, junto a los documentos que analiza, está disponible en www.anuariocdh.uchile.cl

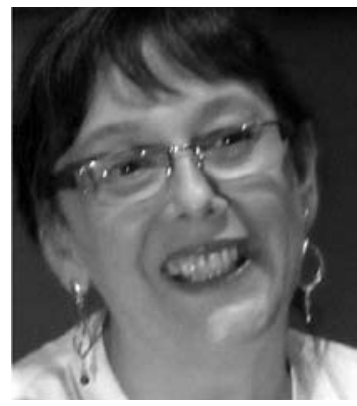

\begin{abstract}
Line Bareiro
Abogada y Politóloga, Magister Artium en Ciencia Política, Universidad de Heidelberg, Alemania. Es investigadora del Centro de Documentación y Estudios (CDE) de Paraguay, integrante del Consejo Asesor del Programa Mujer y Desarrollo del Banco Interamericano de Desarrollo (BID), y consultora del PNUD y OIT. Fue consultora del BID, International Idea, OEA, IIDH-CAPEL, GTZ, UNIFEM, CEPAL. Profesora coordinadora del Seminario "Democracia/s, ciudadanía y Estado en América Latina en el siglo XXI. Análisis de género de los caminos recorridos desde la década del '80 y futuros posibles", PRIGEPP-FLACSO.

linebareiro@gmail.com
\end{abstract}

\section{RESUMEN}

El artículo busca explicar algunos de los problemas que inciden en las dificultades de gobernabilidad de las democracias latinoamericanas. Para estos efectos revisa cómo en el nuevo contexto de la globalización, la consagración y expansión del derecho positivo de los derechos humanos y el avance ciudadano de sectores históricamente marginados han redundado en cambios institucionales profundos en los Estados, los que tradicionalmente habían sido concebidos desde pequeños sectores privilegiados y no contemplaban la universalización de derechos, sino la convivencia con mayorías excluidas.

\section{Introducción}

Vivimos un tiempo de transformaciones. El contexto cambió profundamente a partir de 1989 con la globalización del capitalismo y los cambios demográficos, pero, por sobre todo, continúa mutando el sentido de las ideas más importantes que hacen a la convivencia y a la organización de las sociedades humanas. A lo anterior se suma una cierta ingenuidad en la región respecto de los golpes de Estado en América Latina. Se pensó que eran cosas del pasado, pero esta percepción fue brutalmente modificada después del golpe de Estado en Honduras el 2009, el cual demostró que las instituciones internacionales y los países democráticos no tenían el poder para restituir al presidente legítimamente electo. Es un tiempo de búsquedas, de luchas por el poder y de cambio de sentidos en un continente en el que las desigualdades sociales parecieran seguir sin respuestas efectivas.

En este escenario hay debates imprescindibles, que en América Latina pueden circunscribirse a la gobernabilidad democrática, ya que la fragilidad del sistema político obliga a recuperar la idea de que se deben llevar adelante los proyectos sin romper con las reglas de la democracia. Esa fragilidad alcanzó expresiones dramáticas con el golpe en Honduras, pero existen otros casos en que los sistemas políticos se mueven peligrosamente entre los límites de la democracia y nuevas formas autoritarias. Asimismo, la tragedia de Haití nos mostró las consecuencias del despojamiento de poder soberano a una población empobrecida a los peores niveles del hemisferio. 
Los cambios son difíciles y conllevan tensiones y conflictos, principalmente entre las tendencias concentradoras del poder y aquellas que trabajan por la expansión de los derechos en el mundo. En América Latina se observa una clara extensión de la subjetividad ciudadana, es decir, hay un aumento de personas que han pasado de la aceptación pasiva de ser sin derechos o a acceder solamente a una parte de los mismos, a sentirse sujetos de derecho. En un clima de libertades públicas, no sólo reclaman derechos, sino que se han organizado y convertido en actores sociales y políticos y en algunos casos han accedido al poder del Estado ${ }^{1}$. Estos actores sociales y políticos, además, no sólo se mueven en los espacios tradicionales o en el Estado nacional, sino que se desplazan por la región y el mundo buscando influir en las instituciones multilaterales.

Pero este aumento del sentido de ciudadanía -e incluso de poder en las poblaciones de la regiónha chocado muchas veces con Estados que al mismo tiempo que reconocen cada vez más derechos humanos y se comprometen a garantizarlos, están estructurados de una manera que no permite la vigencia plena de los mismos. Ello ha llevado a la necesidad de repensar los Estados, los sistemas de integración y también a las instituciones multilaterales, cuyas fragilidades se han desnudado en una crisis como la hondureña.

No puede abordarse en un artículo el conjunto de problemas de la democracia latinoamericana, por lo que intentaré en forma breve buscar algunas explicaciones a éstos. Para estos efectos, analizaré cómo en un contexto nuevo como el de la globalización, la consagración y expansión del derecho positivo de los derechos humanos y el avance ciudadano de sectores históricamente marginados obligan a cambios institucionales profundos en Estados, tradicionalmente concebidos desde pequeños sectores privilegiados que no contemplaban la universalización de derechos, sino la convivencia con mayorías excluidas.

Tomaré como ejemplo el desarrollo del sentido de ciudadanía de las mujeres -quienes por cierto no son un sector de la población, sino la mitad de la misma, y que sin embargo históricamente han sido minorizadas y excluidas del poder- y de los pueblos indígenas. Revisaré también, específicamente desde la experiencia de inclusión de la diferencia sexual, los cambios en la democracia y las tensiones que subsisten en los proyectos democráticos. Por último, examinaré los permanentes cambios que desde los años 80 del siglo pasado han vivido los Estados nacionales con motivo de reformas constitucionales y la creación de sistemas de integración y la confusa definición del rumbo a seguir.

\section{Concepciones de ciudadanía y la experiencia del feminismo ${ }^{2}$}

La noción de ciudadanía se ha convertido en uno de los términos con más acepciones y utilización en los últimos 25 años, tanto para el debate académico como para el político e institucional. Desde distintos ámbitos se trata de reconceptualizar la noción de ciudadanía, partiendo de la convicción de que ciudadano y ciudadana son algo más que sujetos de derechos políticos, Ilegando a ser la "democracia de ciudadanía" un concepto orientador de la acción política y para las políticas públicas ${ }^{3}$.

1 Por ejemplo, las demandas de los pueblos indígenas redundaron en la elección de Evo Morales como Presidente de Bolivia.

2 Este artículo está basado en el hipertexto preparado por la autora para el seminario de la maestría virtual de FLACSO/ PRIGEP: BAREIRO, Line. Democracia/s, ciudadanía/s y Estado en América Latina en el siglo XXI. Análisis de género de los caminos recorridos desde la década del 80 y futuros posibles; y en el artículo de BAREIRO, Line y RIQUELME, Jane. Nuevas voceras de la ciudadanía plena. Los procesos de reforma del Estado a la luz de las teorías de género, IULA CELCADEL, Quito, 1997, pp. 17-38.

3 Organización de Estados Americanos/Programa de las Naciones Unidas para el Desarrollo. La democracia de ciudadanía. Una agenda para la construcción de ciudadanía en América Latina. OEA-PNUD, 2009 (sin lugar de edición), se puede consultar en www.democraciadeciudadania.org 
Se trata de un concepto que irrumpió con fuerza en la escena académica y política que anteriormente estaba dominada por otros conceptos. Vale como indicador de tal afirmación que el diccionario de Bobbio, Mateucci y Pasquino ${ }^{4}$ no incluía este vocablo en su edición de 1991. Ese diccionario está considerado como el mejor en ciencia política.

Como la mayoría de los conceptos relevantes, el de ciudadanía también es polisémico e incluso es frecuente escuchar usos tan disímiles como cuando se la utiliza como sinónimo de población y de sociedad organizada o sociedad civil. El significado de esta última noción ha variado también desde Gramsci ${ }^{5}$ hasta el presente, en que Michael Walzer considera que se trata del "espacio de asociación humana sin coerción [...] el juego de redes relacionales -creadas por la familia, la fe, el interés, la ideología- que llenan ese espacio" ${ }^{\prime 6}$.

Quizá lo más interesante de la reapertura del debate sobre ciudadanía sea el análisis de la relación entre los miembros de una comunidad política determinada (organizados o no en distintas asociaciones) y su institucionalidad o Estado. Pues es claro que no hay derechos y obligaciones sin institucionalidad estatal, y sin sujetos sociales de esos derechos y deberes. Como señala Walzer, el Estado crea las relaciones de ciudadanía y forma parte de esa relación, pero son las sociedades las que han luchado por limitar el poder estatal y conquistar derechos, asumiendo responsabilidades.

Respecto de la noción moderna de ciudadanía, existe coincidencia entre la academia y los núcleos feministas de retomar la obra de dos autores relevantes del campo de la ciencia política: Hannah Arendt y Thomas Marshall. La definición de Arendt de los años 40 del siglo XX, de que la ciudadanía es "el derecho a tener derechos" puede ser equiparada actualmente a la de derechos humanos. Desde 1948, es decir, desde la Declaración Universal de los Derechos Humanos, se inicia un nuevo pacto social-internacional que parte de la idea de que toda persona tiene derecho a tener derechos por el solo hecho de ser un ser humano.

La noción desarrollada por Marshall es tal vez la definición más precisa de lo que hoy se entiende y se desea como ciudadanía, por lo menos desde las ciencias sociales, aunque posiblemente reconocida como válida sólo por algunos/as juristas. Esto es, el máximo estatus que una comunidad política da a algunos de sus integrantes ${ }^{7}$. Dicho de otra manera, ciudadanía es la mayor amplitud y profundidad de derechos y de obligaciones que una sociedad organizada como Estado da a una parte de sus integrantes. El esquema de Marshall no ha sido superado por su caracterización de los tres contenidos sustantivos de la ciudadanía: civil, política y social ${ }^{8}$. Nunca es suficiente recalcar que Marshall no ha dicho jamás que esos son los únicos contenidos posibles, sino los que él identificó analizando con una perspectiva de clase social, el proceso de adquisición de derechos en Inglaterra.

4 BOBBIO, Norberto, MATEUCCI, Incola y PASQUINO, Gianfranco. Diccionario de Política. $6^{\mathrm{a}}$ ed. En español, México, Siglo XXI Editores, 1991.

5 Antonio Gramsci (1891-1937) fue el gran teórico marxista italiano. Uno de los ejes de su análisis fue la distinción entre sociedad civil y Estado. Consideraba a la primera como el conjunto de organismos y organizaciones privadas, en tanto que a la sociedad política le correspondía la función de hegemonía ejercida por el grupo dominante (fundamentalmente el Estado) sobre la sociedad.

6 WALZER, Michael. The Idea of Civil Society: A Path to Social Reconstruction. Dissent 38 (primavera), 1991, pp. $293-304$. Traducción de Jane Riquelme.

7 El famoso ensayo "Citizenship and social class", tantas veces citado, es un capítulo del libro de MARSHALL, T.H. y BOTTOMORE, Tom. Class, Citizenship and Social Development. New York, Doubleday, Garden City, 1965, pp. 71-136.

8 Alianza Universidad de España editó el libro de Marshall y Bottomore en castellano, pero lamentablemente no es frecuente encontrar ejemplares en las librerías latinoamericanas y se sigue usando el original en inglés, haciendo traducciones propias, que pueden llevar a ciertas diferencias. 
La extensión de las ideas de Marshall, tanto en la academia como en organizaciones políticas y sociales, radica en que ya había una disconformidad con la restricción de la noción de ciudadanía a los derechos políticos. De esa manera ofrece el argumento central para quienes proponen fortalecer la democracia con mayor participación ciudadana y ésta no limitada a votar y gobernar, sino también a acceder a la justicia, a gozar de un mínimo de bienestar y a tener distintas identidades culturales con igualdad.

Sus grandes argumentos no han sido refutados, aunque hay innumerables críticas y preguntas sobre esos contenidos. Así, por ejemplo, las feministas se han preguntado si los derechos sexuales y los derechos reproductivos podrían subsumirse en esos contenidos, y desde la sociología y la ciencia política, autores como Anthony Giddens, David Held y Bryan Turner se han preguntado quiénes están excluidos de ese máximo. Este último considera ${ }^{9}$ que debe analizarse tanto el origen de la construcción de los derechos (si proviene del Estado y los sectores dominantes, o de la sociedad y los grupos subalternos) como la intensidad de la esfera pública, para comprender el proceso de ciudadanía en un contexto sociohistórico y espacial concreto. Propone un esquema analítico de inclusión/exclusión y público/privado muy afín a los planteamientos del feminismo.

El feminismo es una de las corrientes político-académicas que en los últimos años más ha aportado al debate sobre ciudadanía. En el ámbito anglosajón se ha considerado que la ciudadanía -como la democracia occidental- ha sido concebida y desarrolla por varones, para ellos mismos, y que excluye a las mujeres. Así, a la ciudadanía masculina se le contrapone una ciudadanía femenina, cuya esencia parecería encontrarse en la maternidad ${ }^{10}$.

Un segundo abordaje crítico es el de los derechos de las no ciudadanas, que estudia principalmente el caso de las migrantes, las refugiadas, etc. Se ha desarrollado más en los países europeos y el norte de América, en tanto que en América Latina esta dimensión no ha sido suficientemente abordada pese a los numerosos casos existentes.

Por su parte, las feministas de la igualdad han partido de la idea de que las mujeres pueden llegar a tener iguales derechos luchando por ellos incluso después de su reconocimiento. Esta línea ha tenido una importante influencia en la región con autoras como Celia Amorós y Amelia Valcárcel ${ }^{11}$. En general no se limitan a criticar, sino a proponer una reformulación del Estado o políticas públicas que articulen, por ejemplo, lo productivo y lo reproductivo ${ }^{12}$.

Hay otras perspectivas interesantes, como por ejemplo los trabajos que procuran descifrar qué es lo que significa y lo que contiene la ciudadanía para las mujeres y los hombres en situaciones históricas concretas ${ }^{13}$. Por su parte, Chantal Mouffe concibe a la ciudadanía activa como articulaciones entre sujetos diferentes ${ }^{14}$. Esta noción de ciudadanía contrasta con la visión de ciudadanos pasivos, cuyo énfasis está en los derechos y no en las responsabilidades como actores sociales. La

9 TURNER, B. Outline of a theory of citizenship. En: MOUFFE, Chantal (ed.). Dimensions of radical democracy, London, Verso, 1992.

10 Son referentes de esta corriente autoras como Sara Ruddick y Jean Bethke Elshtain.

11 Algunas obras de Celia Amorós, ampliamente citadas son Hacia una crítica de la razón patriarcal (1985) y Tiempo de Feminismo (1997) y de Amelia Valcárcel Sexo y Filosofía (1991), Del miedo a la igualdad (1993) y La política de las mujeres (1997).

12 "Las ciudades deben ser para producir y también para criar", decía Marina Subirats en su campaña para una concejalía en el municipio de Barcelona.

13 Por ejemplo, Maxine Molineux señala las diferencias entre ser ciudadano o ciudadana en los países del este de Europa (con mucho Estado y poca sociedad organizada), en los islámicos (que a su vez se diferencian mucho entre sí), y los países que desarrollaron la tradición democrática occidental. Por su parte, Jane Riquelme estudió en qué consiste la práctica de la ciudadanía en algunas ciudades y pueblos de Paraguay.

14 MOUFFE, Chantal. Feminismo, ciudadanía y política democrática radical. Debate Feminista Nº 7, México, 1993. 
ciudadanía activa apunta a la articulación de las/los actores sociales en torno a proyectos (más allá de la movilización colectiva) y se vincula estrechamente con la idea de la democracia participativa o ampliación de la democracia.

En la discusión latinoamericana se ha planteado la construcción de una ciudadanía que plantea igualdad en base a las diferencias existentes. De esa manera se considera que en muchos casos el ejercicio del derecho es solamente posible desarrollando mecanismos diferenciados.

Esta problemática no ha sido fácil de seguir, aunque a partir del proceso hacia la $4^{\text {a }}$ Conferencia Mundial de la Mujer realizada en Beijing, China, en 1995, se convirtió en uno de los puntos centrales del debate. Pero las discusiones han estado circunscriptas a espacios muy específicos, aunque es posible que las nuevas tecnologías haya posibilitado una mayor difusión.

Un logro de la visión de las feministas latinoamericanas se reflejó en el "Programa de Acción Regional para las Mujeres de América Latina y el Caribe 1995-2001". En éste se afirma que no habrá plena ciudadanía para las mujeres del continente en la medida en que ésta no es efectiva para todas ellas $^{15}$. Tal vez lo más importante de ese proceso haya sido el reconocimiento generalizado de que la ciudadanía plena no se vincula sólo con la participación política, sino que se trata de "acelerar el logro de la equidad de género y la total integración de las mujeres en el proceso de desarrollo, así como el ejercicio pleno de la ciudadanía en el marco de un desarrollo sustentable, con justicia social y democracia"16.

Se puede reconocer en este momento la existencia de un núcleo de investigadoras-militantes feministas latinoamericanas que están produciendo específicamente sobre ciudadanía, cada cual en sus respectivos países, pero con un activo intercambio de documentos y de debates en los muchos encuentros regionales ${ }^{17}$. Esa dinámica no se agota en un diálogo interno en el movimiento feminista ni con los Estados, sino que es de gran relevancia entre los movimientos sociales en la región y a nivel mundial. El mejor ejemplo de un espacio de necesarias traducciones entre los conceptos de los diferentes actores y el mundo feminista, es el Foro Social Mundial. En este espacio han tenido éxito campañas como la que se ha desarrollado contra los fundamentalismos. Ésta fue iniciada por la Articulación Feminista del MARCOSUR (AFM) en el Foro Social Mundial de 2002 y se extendió en toda la región. En el camino se han sumado organizaciones de Canadá, EE.UU. y de distintos países latinoamericanos y la AFM pasó a ser solamente una más de las organizaciones de la campaña, aunque su liderazgo es reconocido por las demás organizaciones. No obstante, no es sólo por el éxito de esta campaña que este intercambio resultó valioso, sino porque la instalación y superación de la tensión exclusión-inclusión de las mujeres y de sus visiones en las diferentes instancias de organización y los espacios de debate ${ }^{18}$.

15 CEPAL/UNIFEM Programa de Acción Regional para las Mujeres de América Latina y el Caribe, 1995-2001, Santiago, 1995.

16 CEPAL (1995), p. 15.

17 Algunas de ellas son Janine Anderson, Virginia Guzmán, Elizabeth Jelin, Leila Linhares, Maruja Barrig, Natacha Molina, Virginia Vargas, Cecilia Loría, Lilian Celiberti, Montserrat Sagot, Patricia Provoste, Narda Henríquez, Marta Lamas, Sonia Montaño, Gloria Bonder, Dalia Barrera, Clara Murguialday, Gloria Ardaya, Jacqueline Pitangui, Magdalena León, María José Lubertino, Fanny Tabak y Teresita de Barbieri. Hay muchas más, pero la lista sería interminable. Queda por nombrar a Judith Astelarra, quien a pesar de vivir desde hace muchos años en España, integra este núcleo informal desde 1994.

18 Autores como Boaventura de Souza Santos han hecho esfuerzos explícitos de conocer y utilizar el trabajo de las feministas latinoamericanas y, por otra parte, autoras como Charlotte Bunch y Maxine Molineaux tienen una permanente interlocución con las productoras de conocimientos en este campo de América Latina. 


\section{Inclusión, exclusión y los diferentes planos de debate sobre ciudadanía}

Muchas discusiones sobre ciudadanía entrecruzan planos diferentes, o por querer relevar un aspecto se minimiza otro que también es importante. Por ejemplo, los y las juristas tienden a darle todo el peso al estatus jurídico, mientras que las organizaciones sociales ponen el énfasis en las restricciones para el ejercicio de los derechos humanos, restando importancia a las formalidades, y los movimientos indígenas y de mujeres se consideran excluidos si no se contemplan sus reivindicaciones históricas. El feminismo da gran importancia la subjetividad y en casi todos los casos aparece el problema del contenido social, o político o de falta de justicia. Pero todas esas perspectivas son relevantes y no son contradictorias en teoría, aunque pueden serlo en la acción política concreta.

Con una intención pedagógica se ha desarrollado una tipología sobre ciudadanía que integra y diferencia los planos de discusión sobre el tema en: (a) el estatus jurídico, (b) las posibilidades reales de ejercicio, (c) la(s) subjetividad(es) y (d) los contenidos.

Esta tipología se resume en el siguiente cuadro.

\begin{tabular}{|c|c|c|}
\hline Categoría & Variable & Territorialidad institucional \\
\hline Estatus jurídico. & $\begin{array}{l}\text { i) Reconocida formalmente por } \\
\text { el Estado. } \\
\text { ii) No reconocida formalmente } \\
\text { por el Estado en el que vive } \\
\text { una persona. } \\
\text { iii) No reconocida formalmente } \\
\text { por ningún Estado. }\end{array}$ & \multirow[t]{4}{*}{$\begin{array}{l}\text { - Nacional. } \\
\text { - Local. } \\
\text { - Regional. } \\
\text { - Internacional o global. }\end{array}$} \\
\hline $\begin{array}{l}\text { Posibilidades reales } \\
\text { de ejercicio. }\end{array}$ & $\begin{array}{l}\text { i) Plena. } \\
\text { ii) Restringida. }\end{array}$ & \\
\hline Subjetividad/es. & $\begin{array}{l}\text { i) General. } \\
\text { ii) Específica. }\end{array}$ & \\
\hline Contenidos $^{19}$. & $\begin{array}{l}\text { i) Civil. } \\
\text { ii) Política. } \\
\text { iii) Social. }\end{array}$ & \\
\hline
\end{tabular}

En lo sucesivo revisaremos tres de estas cuatro categorías -estatus jurídico, posibilidades reales de ejercicio y subjetividad/es. Cruzaremos el análisis de estas categorías con la variable de territorialidad institucional ${ }^{19}$.

\section{a. Estatus jurídico}

La ciudadanía moderna nació con los Estados nacionales y ese es el marco institucional fundamental hasta hoy. En términos formales, la ciudadanía nacional es el tipo más frecuente: un Estado determinado reconoce como ciudadanos y ciudadanas de ese Estado a determinadas personas, que adquieren los derechos de ciudadanía natural o por naturalización.

Coincidente con la democratización de la región en los años 80 y 90 del siglo XX, se desarrollaron procesos de descentralización y en varios países se fortalecieron las municipalidades. Es interesante

19 Conforme a la clasificación de T.H. Marshall. 
pensar que hay una ciudadanía local que puede ser diferente de la nacional. Por ejemplo, en algunos países ${ }^{20}$ se admite que personas extranjeras con una cantidad determinada de años de residencia en el municipio puedan votar para elegir a las autoridades locales o postularse para ser electos/as para esos cargos.

En síntesis, el estatus jurídico consiste en el reconocimiento formal por parte de algún Estado de que los y las integrantes de un colectivo determinado tienen los derechos de ciudadanía. El estatus se cruza con las tres variables anticipadas en la tabla: (i) que éste se encuentre reconocido formalmente por el Estado; (ii) que no esté reconocido formalmente por el Estado en el que vive la persona, y (iii) que el estatus no esté reconocido por ningún Estado.

El problema del estatus pareciera estar solucionado en la región, ya que formalmente no se explicita la exclusión de ningún colectivo social, pero la realidad nos indica otra cosa. Situaciones tan graves como la apatridia o el no reconocimiento del estatus de ciudadanía de una persona por parte de ningún Estado no afectan solamente a pueblos lejanos, como el palestino. En un pasado cercano, hijos e hijas de miles de exilados latinoamericanos en Europa han estado sin nacionalidad por nacer en un país en el rige el $i u s s{ }^{21}{ }^{21}$ y no haber habido posibilidad de inscribirlos en los consulados de las dictaduras que asolaron la región. Pero a partir del terremoto de Haitín se hizo visible una de las principales reivindicaciones de los movimientos por los derechos de la niñez y el movimiento feminista haitiano-dominicano: la necesidad de que República Dominicana reconozca como nacionales a los hijos e hijas de mujeres haitianas nacidos en este país ${ }^{23}$.

Esta falta de reconocimiento de la nacionalidad es discriminatoria, ya que la Constitución dominicana establece en su artículo 11 que "todas las personas que nacen en el territorio dominicano son dominicanas, excepto los hijos de diplomáticos y personas en tránsito".

El caso de los niños y niñas de madre haitiana nacidos/as en la República Dominicana es, en cierto sentido, similar al proceso de adquisición del estatus de ciudadanía por parte de las mujeres en la región a lo largo de las primeras seis décadas del siglo XX. Era muy frecuente que este debate se moviese en un registro similar, ya que no había impedimento constitucional para el reconocimiento y ejercicio de los derechos políticos de las mujeres. No obstante, en el caso de la ciudadanía de las mujeres la negación del derecho estaba incluida en la legislación electoral, en tanto que en el caso de los niños y niñas de madre haitiana nacidos/as en la República Dominicana, la negación de la nacionalidad, y por ende de la ciudadanía, no figura en ninguna ley, sino que es una práctica sistemática de la administración pública.

Las personas migrantes no son ciudadanas en el país en el que viven, pero de todas maneras tienen el estatus de ciudadanía en su país de origen. No es el caso de colectivos a los cuales se les niega el derecho en el país en el que nacieron.

20 En Argentina y Paraguay, por ejemplo.

21 Es frecuente que en debates con sectores populares aparezcan en este punto los problemas de registro que existen. Sin embargo, para esta clasificación ello forma parte del plano del ejercicio de los derechos y es producto de las restricciones de la propia institucionalidad estatal y no es un problema de estatus.

22 El 12 de enero de 2010 se produjo un terremoto en Haití, que destruyó lo poco que había de infraestructura y de instituciones. Las muertes superaron las 200.000 personas en el país más pobre del hemisferio occidental.

23 Por ejemplo, el manifiesto del 8 de marzo de 2010 del Comité pro niñez dominico-haitiana Grito de los excluidos/as "Ningún ser humano es ilegal". Se puede rescatar que la principal líder del Movimiento de Mujeres Dominico-Haitianas (MUDHA), Solange Pierre, conocida en Dominicana como Sonia Pierre, que trabaja por los derechos humanos de haitianas/os y sus hijas/os que viven y sufren discriminación en la República Dominicana, ha recibido en 2009 el premio Robert Kennedy de DDHH y el 10 de marzo de 2010 el Premio Internacional "Mujeres Valientes" de manos de la Secretaria de Estado de los EE.UU., Hillary Clinton. 
Lo nuevo y complejo del debate sobre el estatus jurídico es la construcción de una ciudadanía regional. Esta misma se ha producido como efecto de los procesos de integración en los cuales una persona adquiere doble ciudadanía, la propia nacional y la regional. El caso de mayor desarrollo de una ciudadanía regional es el de la Unión Europea (UE), aunque no llegó a aprobarse una Constitución que hubiese permitido perfeccionar el sistema. En América Latina se superponen las instituciones multilaterales sin llegar a un desarrollo que permita pensar que en un tiempo más o menos previsible se llegará a una consagración de ciudadanía regional.

En realidad pareciera ser que la ciudadanía regional se está construyendo mucho más en relación a la justicia, es decir, de ciudadanía civil siguiendo a Marshall, antes que a una ciudadanía política o social. El motivo de esta afirmación es el funcionamiento de sistemas regionales de derechos humanos. El Sistema Interamericano de Protección de Derechos Humanos, que funciona subsidiariamente a los Estados ante violaciones de derechos humanos es, probablemente, la más importante forma de estatus de derechos reconocido a las personas en nuestra región.

No existe aún una ciudadanía internacional o global, ya sea política o social, justamente porque no existe una institucionalidad democrática internacional que gobierne a la economía global y haya un estatus igual de todas las personas. En la práctica rige la "ley del más fuerte" en las relaciones internacionales ${ }^{24}$.

Numerosos autores y personalidades se han pronunciado a favor de la construcción de una institucionalidad democrática global. Un caso muy conocido es el del ex presidente brasileño, Fernando H. Cardoso, quien ha instado en más de una oportunidad a la construcción de un orden democrático a escala internacional. Por su parte, David Held desarrolla un alegato por la democracia cosmopolita como un imperativo del bien democrático. En este sentido, plantea la posibilidad de construir una estructura común de acción política que sea trasnacional, en la que habría nuevas formas y niveles de gobierno ${ }^{25}$.

En el campo internacional es interesante cómo se ha desarrollado también una ciudadanía sin estatus, vinculada a las resoluciones de las Naciones Unidas. Este es un caso en el que un difuso movimiento de mujeres ha conseguido convertir un año dedicado a las mujeres (1975) en una década (1975-85), una convención específica (Convención Sobre la Eliminación de Todas las Formas de Discriminación Contra la Mujer, CEDAW por su sigla en inglés), y documentos de políticas públicas como las Estrategias de Nairobi (1985) y la Plataforma de Acción de Beijing (1995). Esta última ha sido evaluada cada cinco años.

Aun cuando el sistema de protección de derechos humanos de las Naciones Unidas solamente observa y recomienda a los Estados, los Comité de seguimiento de los pactos y convenciones escuchan a los Estados y también a la sociedad organizada y en los casos en los que se cuenta con protocolos facultativos, reciben casos y llevan adelante procedimientos para emitir informes sobre éstos. Es decir, también en lo internacional se ha ido construyendo una institucionalidad ante la cual las personas pueden defender sus derechos. Esto es más claro aún con respecto a la Corte Penal Internacional, que comenzó a funcionar el 1 de julio de 2002 y tiene competencia para juzgar, entre otros, los crímenes de genocidio y lesa humanidad.

Se puede ciertamente alegar que mientras que el país más poderoso del mundo no se someta a la jurisdicción de esos tribunales, ni ratifique los instrumentos de derechos humanos, no hay garantías para nadie. No obstante, no es poca cosa que más de la mitad de los países que integran

\footnotetext{
24 Hay países que determinan sólo o con algunos pocos aliados si los gobernantes de otro país "se portaron mal" y por tener poder, bombardean a la población de ese país.

25 HELD, David. La democracia y el orden global. Barcelona, Paidós, 1997, pp. 265-283.
} 
las Naciones Unidas estén sometidos a la jurisdicción de la Corte Penal Internacional y que la Convención sobre Derechos del Niño fuese ratificada por todos los Estados del mundo, menos $\operatorname{dos}^{26}$.

\section{b. Posibilidades reales de ejercicio}

Talcott Parsons desarrolló el concepto de ciudadanía plena. Él abordó esta cuestión con el objeto de analizar la lucha por los derechos civiles de los negros norteamericanos en la década de 1960 en EE.UU. Lo relevante es que la consagración legal de derechos y el aumento en la participación política formal, aun siendo condiciones necesarias para la inclusión de colectivos en la comunidad política, son insuficientes ${ }^{27}$. Ejemplo de ello es el tipo de discriminaciones sufridas por la comunidad negra. Este fructífero concepto fue desarrollado pensando en un colectivo marginado del uso completo de sus derechos.

El sociólogo norteamericano señaló también que en el proceso de integración de la comunidad negra fue clave el rol jugado por lo físico/simbólico, en tanto indicador de inferioridad intrínseca. Según Parsons, ese tipo de problemas no lo habían experimentado otras comunidades discriminadas, como la judía y la católica. Al respecto, las mujeres conocen muy bien lo que es la discriminación justificada por características biológicas.

El concepto de ciudadanía plena utilizado por Parsons se refiere a membresía plena en "la sociedad comunitaria"28. Esta es "una categoría de compromiso de los miembros con una colectividad en donde están asociados y de los miembros entre sí. Es el enfoque de las lealtades que no tienen que ser absolutas, y de hecho no pueden ser, pero sí debe ser prioritaria. Para que la estructura asociativa funcione tiene que estar de acuerdo con los valores comunales de la sociedad: los miembros están comprometidos porque la estructura implementa sus valores tanto como organiza sus intereses en relación a otros intereses ${ }^{\prime 2}$.

Según Parsons, una vez que se moviliza una situación de marginación que agita la escena sociopolítica, no pueden predecirse las consecuencias. En ese proceso, distingue entre asimilación e inclusión y analiza el paso de una a la otra en el proceso de construcción de ciudadanía. La primera consiste en la exigencia de que, para reconocer como iguales a los diferentes, éstos deben parecerse lo más posible a quienes ya pertenecen a la comunidad, en tanto que la inclusión acepta a cada cual con sus características específicas y le otorga los mismos derechos.

El paso de una situación a la otra supone un proceso complicado y debe llegarse al punto en el que no sea contradictorio tener varias membresías, algunas de ellas adscriptivas (como la etnicidad) y otras más voluntarias, como la religión. Todas las membresías se combinan en una estructura social pluralista.

La ciudadanía plena no implica por lo tanto una ilusoria plenitud de derechos, sino la titularidad y el ejercicio efectivo de derechos que son garantizados por el Estado.

La ciudadanía restringida, en cambio, es la dificultad o imposibilidad de ejercer derechos por parte de personas que declarativamente son ciudadanas con todos los derechos que implica el estatus. Las restricciones pueden provenir de la sociedad, pero también del propio Estado. Se puede plantear

26 No han ratificado la Convención sobre los Derechos de los Niños Somalia y Estados Unidos.

27 PARSONS, Talcott. Full Citizenship for the Negro American? En: Sociological Theory and Modern Society. New York, The Free Press, 1967, pp. 422-465. Se pudo llegar a una copia de este trabajo (muy poco difundido en América Latina) gracias a la generosidad de Gilberto Giménez, quien le entregó un ejemplar a Jane Riquelme, al saber que ella estaba trabajando sobre el tema.

28 La palabra en inglés es "societal community".

29 PARSONS, Talcott, op. cit., nota 28, p. 424. Traducción de Jane Riquelme. 
una infinidad de razones, situaciones y profundidad vinculadas a la restricción. En el máximo nivel estarían las personas que no pueden ejercer ninguno de sus derechos, ya sea por la exclusión del sistema educativo, la pobreza extrema, el racismo, la homofobia, el etnocentrismo, el sexismo, o cualquier otra causa.

Dentro de los sectores afectados por éstas u otras motivaciones se pueden observar grados diferenciados de restricción. Por ejemplo, actualmente las mujeres, los pueblos indígenas y las poblaciones de afrodescendientes, con sus organizaciones y sus luchas, han llegado a un cierto nivel de reconocimiento, manteniéndose sin embargo una desigual distribución de la riqueza y las oportunidades como un factor que impide el ejercicio de la plena ciudadanía a la mayoría de esos colectivos.

Entender la razón y el origen de las restricciones al ejercicio de la ciudadanía puede ser fundamental para superarlas. Si éstas provienen de la propia institucionalidad es relativamente más factible superar el problema siempre y cuando haya poder suficiente para el cambio y se encuentren los mecanismos adecuados. Por ejemplo, en Paraguay la población que habla solamente guaraní, pero que no es precisamente de la nación guaraní, supera el $10 \%$ de la población, que a su vez coincide con la población que vive en condiciones de extrema pobreza, no tiene acceso a la justicia y, en fin, al ejercicio de la mayor parte de sus derechos. A pesar de que el guaraní es lengua oficial en las oficinas públicas, no era obligatoria la atención en guaraní. En el último año la Secretaría de la Función Pública tiene como uno de sus tres ejes la atención sin discriminaciones y una de las medidas que ha implementado es promover la enseñanza de guaraní libre de contenidos discriminatorios. Políticas similares han sido adoptadas también en Formosa y Corrientes, provincias argentinas que también han consagrado al guaraní como lengua oficial junto al castellano. Son políticas creativas y muy recientes, que pueden tender a una integración que permita un ejercicio pleno de la ciudadanía, cuyos resultados deberán ser evaluados en un tiempo más.

Un caso especialmente relevante es el del acceso igualitario de las mujeres a cargos de representación y a mandatos. La conquista de los derechos políticos fue comprendida por las propias mujeres como conquista del derecho a decidir quién gobierna mediante el ejercicio del sufragio y no necesariamente del derecho a gobernar. Ciertamente más que de la institucionalidad, la restricción provenía de la cultura política y la aceptación de la norma patriarcal de que la política es un espacio exclusivamente masculino. Recién cuando subjetivamente las feministas y parte de las mujeres políticas rompieron con la aceptación de la exclusión se comenzó a pensar, diseñar, conquistar legalmente y aplicar mecanismos que permitieron pasar en brevísimo tiempo de una representación de menos del $10 \%$ al $40 \%$ en la representación parlamentaria en países como Costa Rica y Argentina.

Ahora bien, la cuestión se vuelve mucho más compleja si se llega a la conclusión de que la restricción para la universalización de los derechos está en el propio diseño del Estado, lo que obliga a un cambio profundo de la institucionalidad estatal. Ese ha sido justamente el planteamiento en Bolivia y en Ecuador para las reformas constitucionales del siglo XXI. Sería relevante la comparación de la situación de partida de ambos casos, de los procesos constituyentes, de los resultados plasmados en las nuevas constituciones de ambos países y los efectos de estos cambios. Pero tomando solamente una declaración contenida en ambas constituciones, la de ser Estados plurinacionales, es posible observar, aún con disidencias, una alta legitimidad de las reformas en el movimiento indígena boliviano y constantes denuncias de incumplimiento del Estado plurinacional en Ecuador ${ }^{30}$.

30 La Asamblea Extraordinaria de la CONAIE expresó en el considerando su Resolución del 26 de febrero de 2010: “Que los Pueblos y Nacionalidades indígenas somos parte de este Estado aun antes de la constitución del Estado ecuatoriano. 


\section{c. Subjetividad/es}

Esta categoría es posiblemente la más difícil de la tipología propuesta, ya que en este caso se pone en el centro la relación del sujeto con los derechos fundamentales y las obligaciones del Estado. ¿Pueden construirse ciudadanías específicas a partir de derechos específicos? ¿O serían solamente la forma diferencial en que dichos derechos afectan a diferentes sujetos?

Este tema tiene que ver con las identidades ciudadanas, que en idioma guaraní se puede resumir en la relación entre el nosotros incluyente del interlocutor (ñande) y el nosotros excluyente del interlocutor (ore). La ciudadanía está pensada en términos de reconocimiento de derechos a cada individuo por parte de la institucionalidad estatal y cada persona (che) puede ejercerlos. Sin embargo, muchos de los derechos se ejercen colectivamente y las restricciones provienen justamente también de la pertenencia a ciertos colectivos. Por ejemplo, el derecho al voto es parte de los derechos políticos y se ejerce individualmente. Pero para que se pueda ejercer ese derecho se precisa de organismo(s) estatal(es) electoral(es) que organice(n) y juzguen las elecciones. Y se elige a personas organizadas en asociaciones políticas legalmente constituidas. Así una campaña electoral en un juego entre varios ore por el gobierno del ñande.

Desde el punto de vista de la subjetividad, encontramos una ciudadanía general donde los derechos deben ser los mismos para todas las personas que integran una determinada comunidad política. En ese sentido, cada derecho está hoy pensado en la universalidad.

Una subjetividad específica de ciudadanía piensa principalmente en derechos para un grupo determinado, generalmente como consecuencia de que el reconocimiento del estatus de ciudadanía e incluso el reconocimiento de derechos universales no genera automáticamente mecanismos que contemplen la especificidad de las situaciones en las que tal grupo se encuentra, lo que redunda en que no puedan ejercer efectivamente los derechos.

Por ejemplo, es sabido que una de las luchas más importantes de los pueblos indígenas, que los diferencian de otros sectores sociales, es su demanda de territorio. Así han construido una ciudadanía específica, la que para ser plena requiere que el colectivo goce además de todos los otros derechos de ciudadanía general. Un buen ejemplo de subjetividad y derechos nacionales y étnicos es el caso de Panamá, donde hay cuatro comarcas indígenas determinadas por ley y una importante participación indígena sostenida en la Asamblea Legislativa proviene de pueblos indígenas como los kuna y los emberá.

También se puede incluir en esta variable a las mujeres, pues su identidad ciudadana se forjó alrededor de la conquista de derechos específicos, por ejemplo, aquellos que tienen que ver con su cuerpo. Ciertamente, numerosos derechos sexuales y derechos reproductivos son tanto para hombres como para mujeres, pero el permiso de maternidad con goce de sueldo, por un tiempo previo y posterior al parto, es exclusivamente para las mujeres y ellas han peleado específicamente por ese derecho.

Que el artículo 1 de la Constitución de la República de Ecuador instituye el carácter Plurinacional e intercultural del Estado. Que el Convenio Nº 169 de la OIT, está en plena vigencia desde 1998. Que la Declaración de las Naciones Unidas sobre los derechos de los pueblos indígenas está vigente desde septiembre del 2007. Demandar al gobierno de la 'revolución ciudadana' y del 'socialismo del siglo XXI' por no haber modificado el Estado Colonial y seguir fortaleciendo el modelo neoliberal capitalista, traicionando al pueblo ecuatoriano, a las comunas, comunidades, pueblos, nacionalidades indígenas, afro ecuatorianos y montubios". 


\section{Cambios en los Estados nacionales}

En el análisis de los permanentes cambios que desde los años 80 del siglo pasado han vivido los Estados nacionales con motivo de reformas constitucionales y la creación de sistemas de integración, es importante explicitar ciertos puntos de partida sobre los sistemas democráticos y América Latina que revisaré más adelante:

- La noción de democracia es un producto histórico que nació en un pueblo concreto, basada en la idea de soberanía popular;

- La noción moderna de ciudadanía une el pluralismo ideológico a la concepción inicial de soberanía popular;

- La fragilidad histórica de las democracias latinoamericanas se explica tanto por problemas estructurales como de cultura política;

- La revalorización de la democracia, el extenso consenso social-político sobre la misma y su consagración como sistema político en muchos Estados del continente se produjo después de décadas de dictaduras y conflictos armados y de violaciones masivas y sistemáticas de los derechos humanos;

- El consenso democrático incluyó la consagración de libertades públicas y sistemas de elecciones competitivas como forma de selección de gobernantes, pero actualmente los proyectos de cada país se han vuelto disímiles y existen dificultades para constituir sistemas de integración regional sólidos;

- Actores políticos antes excluidos se han convertido en protagonistas de los procesos de cambios políticos y han obligado no sólo a adoptar mecanismos que permitan su inclusión, sino a una revisión de la noción de democracia.

i) Un sistema político con autor

La primera expresión histórica de democracia, su punto de partida, se gestó en la Grecia del siglo $\mathrm{V}$ antes de Cristo. El gran mérito de los griegos fue haber concebido un sistema político no autocrático en el que la soberanía estaba radicada en un grupo de ciudadanos, en un momento histórico donde todas las naciones eran gobernadas por soberanos cuya legitimidad provenía generalmente de un designio de los dioses y las diosas. La descripción realizada por Pericles en el año 431 AC., no deja dudas acerca de la autoría del régimen político que se extendería en el mundo dos mil años más tarde:

"Tenemos un régimen de gobierno que no envidia leyes de otras ciudades, sino que somos ejemplo y no imitamos a los demás. Su nombre es democracia, por no depender el gobierno de pocos, sino de un número mayor; de acuerdo con nuestras leyes, cada uno está en situación de igualdad de derechos en las disensiones privadas, mientras que según el renombre que cada uno tenga, a juicio de la estimación pública, es honrado en lo público"31.

\section{ii) Soberanía popular y pluralismo}

Según la filósofa belga Chantal Mouffe ${ }^{32}$, la noción de democracia moderna puede sintetizarse como soberanía popular con pluralismo. La definición de Chantal Mouffe agrega al aporte griego

31 PERICLES. Discurso fúnebre. Incluido in extenso en Tucídides en Historia de la Guerra del Peloponeso.

32 MOUFFE, Chantal. Ciudadanía democrática y comunidad política. En: LACLAU, Ernesto y MOUFFE, Chantal. La democracia de fin de siglo. Asunción, CDE, 1991, p. 19. 
de soberanía popular, el pluralismo como lógica del liberalismo político. Así, según la autora, en la democracia moderna "[...]se habla de 'articulación' de dos lógicas por cuanto no es posible deducir el pluralismo de la noción de soberanía popular o concepción clásica de la democracia"33. El pluralismo implica el reconocimiento y, por cierto, la legalidad de la existencia de diferentes visiones, ideas, grupos de interés, etc., al interior de una sociedad. En las democracias modernas, por lo tanto, es imprescindible que distintos grupos organizados puedan tener iguales derechos de competir por dirigir la institucionalidad de la comunidad política, es decir, el Estado.

\section{iii) Contradicción estructural y choque cultural}

Con excepción de pocos países que pudieron mantener periodos de varias décadas de democracia, el continente vivió por lo menos un siglo de fluctuación entre democracias y dictaduras. Para comprender ese proceso rescatamos, por una parte, el análisis de Quijano y el de Lechner, sobre la tensión entre modernidad y modernización. Por otra, recurrimos a una breve revisión de la cultura política.

Aníbal Quijano ${ }^{34}$ recuerda que la modernización constituyó en América Latina un argumento de presión por parte de agentes externos a la región para lograr transformaciones acordes a las necesidades del capital. La modernidad, en cambio, fue producto de la intelectualidad (latinoamericana y de otras regiones), que moldeó la utopía de una sociedad sin arbitrariedades ni oscurantismo. Así, mientras en Europa la modernidad y la ciudadanía avanzaron con el desarrollo capitalista, en América Latina se produjo una brecha entre los planteamientos democráticos y el hecho de que quienes ocupaban el poder fuesen los elementos más ligados a la arbitrariedad y el despotismo. Esa situación condujo, de hecho, al quiebre de las democracias en América Latina y a las dictaduras militares.

Lechner muestra el otro extremo, el de la modernización sin modernidad, esto es, cuando el desarrollo capitalista tiene lugar sin despliegue de la democracia y del ejercicio ciudadano ${ }^{35}$. Según el autor chileno-alemán ${ }^{36}$, hay despotismo cuando hay desarrollo capitalista pero la sociedad misma no puede decidir qué se debe hacer, cómo se debe actuar para realizar la idea de futuro que se propone.

No menos importancia que los factores antes descritos tiene el componente histórico de la cultura política del continente de pretensión de poder absoluto: el deseo de eliminar al competidor, a quien es diferente, en lugar de reconocer al "otro" como igual y titular de los mismos derechos y obligaciones.

En la derecha se aceptaba la democracia, pero en tanto y cuanto no hubiese riesgo de que ganase la izquierda, pues en ese caso, golpeaban las puertas de los cuarteles, como en los derrocamientos de Salvador Allende en Chile, de Jacobo Arbenz en Guatemala, y de Joao Goulart en Brasil, por citar unos pocos casos. Por su parte, en la izquierda predominaban ideas que en última instancia implicaban el deseo de poder absoluto. Algunos sectores operaron directamente fuera del sistema político y despreciaban a la democracia burguesa y la democracia formal, diferenciándola de la democracia sustantiva. Otros sectores de izquierda participaban en partidos que se presentaban a elecciones y a los que el primer grupo consideraba como reformistas. Con la participación de los sectores reformistas de izquierda y las luchas del movimiento obrero, se conquistó la mayor

\footnotetext{
33 Ídem.

34 QUIJANO, Aníbal. Otra noción de lo privado, otra noción de lo público. Revista de la CEPAL (35), 1989.

35 LECHNER, Norbert. El aporte de las organizaciones no gubernamentales de desarrollo (ONGD) a la vida democrática de América Latina. En: Ayuda Obrera Internacional, Solidaridad Internacional y Solidaridad Democrática: De un pasado común a un futuro mejor. Europa-América Latina 1992, IAO/SI/SD, Huelva.

36 LECHNER, Norbert. Los patios interiores de la democracia. Santiago, FLACSO, 1988, p. 189.
} 
parte de los derechos sociales en nuestros países. No obstante, muchos de sus adherentes consideraban que esa participación era solamente una cuestión táctica y que el real objetivo era hacer la revolución que sacara todo el poder a la oligarquía y la burguesía. Y, por supuesto, a sus expresiones políticas.

\section{iv) Derechos humanos para valorar la democracia}

Las arbitrariedades y violaciones masivas y sistemáticas a los derechos humanos cometidas por las dictaduras derechistas o con motivo de las guerras civiles en la región durante las décadas de los 60, 70 y 80 -también los 90 en el caso de Perú- condujo a un cambio significativo en la valoración de la democracia como un sistema político necesario para el goce de los derechos humanos. Es lo que Norbert Lechner considera como el paso de la revolución a la democracia. Este paso no sólo es válido para la izquierda, sino también para la derecha, que aprendió que no tendría ya legitimidad como conductora del despotismo. Este giro, en cierta manera, surge de la necesidad, porque debido al rechazo al horror que se vivió durante las dictaduras se logró un consenso por la democracia, que implica la aceptación del pluralismo y la tolerancia.

\section{v) El consenso democrático y la diversidad de proyectos}

En los primeros años, el consenso democrático incluyó la necesidad de consagrar las libertades públicas y las elecciones competitivas como forma de selección de gobernantes. La experiencia histórica nos muestra que no hay una única manera de generar un sistema democrático, aunque la pobreza del debate que ha habido al respecto en la región en la última década del siglo XX, nos ha llevado a lo que bien señala Alain Touraine como falta de conciencia sobre la existencia de diversos proyectos democráticos y la ausencia de debates sobre democracia social. Al no haber perspectivas nuevas, la idea misma de democracia se degrada hasta reducirse en una "libertad de consumo, [en un] supermercado político" 37 .

Ciertamente, las distintas formas de desarrollar un sistema democrático se basan en diferentes ideas sobre la ciudadanía y las relaciones entre el Estado y la sociedad ${ }^{38}$. Por ejemplo, si alguien considera que todas las personas mayores de 18 años tienen en la práctica los mismos derechos, pues así está en la ley, desarrollará políticas muy diferentes que quienes basados en datos de la realidad, considera que pese a la igualdad legal formal hay desigualdades en la sociedad.

Siguiendo la propuesta de Larry Diamond y Juan $\operatorname{Linz}^{39}$, en los distintos mecanismos y sistemas políticos pueden identificarse algunas condiciones básicas de la democracia. Entre ellas:

- La existencia de una competencia significativa y extensa en intervalos regulares y sin coerción, entre individuos y grupos organizados (especialmente partidos políticos) para todos los puestos de poder efectivo en el Estado;

- Un alto índice de participación política en la selección de líderes y de las políticas públicas, a realizarse en elecciones libres y justas, de manera tal que ningún grupo social de adultos sea excluido;

- Un nivel de ejercicio de libertades civiles y políticas - de expresión, de prensa, de asociaciónsuficiente para asegurar la integridad de la competición política y de la participación.

37 TOURAINE, Alain ¿Qué es la democracia?, Fondo de Cultura Económica, Buenos Aires, 1995, p. 18.

38 BAREIRO, Line y RIQUELME, Jane. Nuevas voceras de la ciudadanía plena. En: Los procesos de reforma del Estado a la luz de las teorías de género. IULA/CELCADEL, Quito, 1997, pp. 17-38.

39 DIAMOND, Larry y LINZ, Juan. Introduction: politics, society, and democracy in Latin America. En: DIAMOND, L., LINZ, J.J. y LIPSET, S.M. (eds.), Democracy in Developing Countries. Latin America. Vol. 4, Lynne Rienner Publishers, Boulder, 1992, p. xvi. La traducción es de Jane Riquelme. 
La literatura rescata diversos modelos de democracia y pareciera ser que la diferencia radica principalmente en el nivel de participación ciudadana y los mecanismos habilitados para esa participación. David Held consideraba hace ya veinte años ${ }^{40}$ que la complejidad de proyectos democráticos podría agruparse en cuatro grandes líneas -legal, participativa, republicana-cívica y radical-pero éstas no han marcado las pautas del debate ni académico ni político en América Latina.

En los primeros años de las democracias de la región, los énfasis estuvieron en las instituciones políticas y en los mecanismos democráticos. La tendencia fue garantizar elecciones competitivas, consagrar derechos humanos y formar parte de la comunidad internacional. No obstante, al mismo tiempo que se consagraban un conjunto de garantías constitucionales y mecanismos de democracia participativa o directa como el referéndum, el plebiscito, la iniciativa legal popular y la revocatoria de mandato, y muchos Estados se declaraban como "Estado social y democrático de derecho", se ponían en práctica ajustes estructurales a las economías y América Latina llegó a ser la región más desigual del mundo.

Este periodo se cerró con demostraciones regionales de la voluntad de mantenerse como comunidad democrática. Por ejemplo, en el año 2001 se aprobó en el marco de la OEA la Carta Democrática Interamericana ${ }^{41}$, y en el MERCOSUR (Mercado Común del Sur) también se incluyó una cláusula democrática. Sin embargo, a diferencia de las reformas constitucionales de finales del siglo XX, las del siglo XXI tienden más a reconcentrar poder en el Ejecutivo y a establecer la legalidad de una o más reelecciones presidenciales, que a una profundización de la democracia. Posiblemente la excepción sea el caso boliviano.

En países como Colombia, Venezuela y Nicaragua hay importantes restricciones a las libertades públicas y si bien se mantienen las elecciones como forma de selección de los gobernantes, comienza a haber serios cuestionamientos sobre las restricciones al ejercicio de la ciudadanía. Se trata de sistemas políticos que se mueven constantemente entre la democracia y el autoritarismo, como antes ha sido el caso de Fujimori en Perú.

En la actualidad, el único quiebre democrático ha sido el hondureño en el año 2009, en el cual los militares apresaron mientras dormía al presidente electo, lo embarcaron en un avión y expulsaron del país. Los golpistas permanecieron en el poder durante medio año a pesar de no contar con el reconocimiento de ningún país del mundo y de los esfuerzos infructuosos de la OEA y las Naciones Unidas de restablecer la democracia. Notablemente, la acusación de los golpistas al presidente Zelaya se centraba en su empecinamiento en realizar una consulta popular a pesar de existir una prohibición expresa de consultar sobre ciertos temas.

vi) Inclusión de nuevos actores conduce a reformas y cambios en el concepto de democracia

La pregunta acerca de qué diferencias societarias son incluidas en el sistema político nos conduce a pensar que las diferencias son incluidas de manera muy distinta en un sistema democrático y que la forma de inclusión tiene su propio proceso histórico. Así, por ejemplo, la inclusión en el sistema político de partidos confesionales o religiosos no lleva a una profundización de la democracia, sino que más bien conduce a gobiernos neoteocráticos que terminan excluyendo a las mujeres y a otros colectivos sociales como homosexuales, lesbianas y personas transexuales e impidiendo el goce de sus derechos.

40 HELD, David. Models of democracy. Stanford University Press, Stanford, 1987. Del mismo autor Citizenship and autonomy. En: Social theory of modern societies: Antony Giddens and his critics [s.n.], 1989.

41 Carta Democrática Interamericana. Aprobada en la primera sesión plenaria, celebrada el 11 de septiembre de 2001. http://www.upd.oas.org/documents/basic/cartademocratica.htm 
Algunas minorías buscan su inclusión en el sistema político mediante la adquisición de liderazgo y de convencer al electorado que es importante que los derechos de su colectividad estén representados, como ha sido en el caso de las personas discapacitadas en Costa Rica.

Pero sin lugar a dudas, dos sectores históricamente excluidos han logrado una inclusión que ha transformado el mapa político: los pueblos indígenas y las mujeres. Los pueblos indígenas han logrado, principalmente en Bolivia y Ecuador, un importante nivel de liderazgo que ha transformado las instituciones y las prácticas políticas. Por su parte, las mujeres no son un sector separable, sino la mitad de la población y están presentes en las organizaciones de todo el espectro político ${ }^{42}$. Si bien los partidos feministas por lo general no han tenido éxito, sí lo ha tenido el discurso sobre la necesidad y legitimidad de la participación de las mujeres en la política, específicamente, a través de medidas de acción afirmativa como las cuotas. En 1991 Argentina aprobó la "Ley del Cupo Femenino" convirtiéndose en el primer país del mundo en consagrar por ley medidas de acción positiva obligatorias para todos los partidos políticos. De ahí en adelante las cuotas de participación política de las mujeres se aprobaron por ley en 12 países de la región, con regulaciones y resultados diferentes.

En el balance de cuotas publicado en el año 200943, que analiza la información de los organismos electorales, se llegó a la conclusión de que para que funcionen las cuotas debe existir (i) un estado de derecho, (ii) una ciudadanía activa de las mujeres dispuesta incluso a incoar acciones judiciales en caso de incumplimiento de la legislación de cuotas, (iii) una opinión pública favorable y, finalmente, (iv) mecanismos de cuotas diseñados para funcionar efectivamente en el sistema electoral en el cual se insertan. En los casos más exitosos de aplicación de cuotas, Argentina y Costa Rica, se llegó a una participación parlamentaria de las mujeres de un $40 \%$.

Pero las cuotas son medidas compensatorias concebidas como temporales que coinciden con el concepto del artículo 4 de la Convención Sobre la Eliminación de Todas las Formas de Discriminación Contra la Mujer (CEDAW por su sigla en inglés), que habla de medidas temporales para acelerar la igualdad de facto. La idea de paridad, en cambio, está pensada como permanente y parte del concepto mismo de democracia.

La idea de la paridad es integrar la diferencia sexual al sistema electoral de manera similar a las diferencias territoriales. Si bien la gran diferencia en disputa en las elecciones sigue siendo la ideológica o de asociaciones políticas, ningún sistema electoral de la región ignora que el territorio debe estar representado. Generalmente se fija la cantidad de representantes conforme a la población de las regiones, departamentos, provincias o estados federados, pero se hace la salvedad de que ninguna región quedará sin representación. Lo que electoralmente propone la paridad es que todos los partidos y movimientos políticos que buscan el voto ciudadano deben integrar sus candidaturas con un 50\% de hombres y un 50\% de mujeres.

Apenas en 1998 se aprobó la primera democracia paritaria en Francia, sin que hasta ahora haya funcionado efectivamente la paridad. Pero a la fecha ya son tres los países latinoamericanos que han consagrado la paridad: Bolivia y Ecuador en sus constituciones, y Costa Rica en la ley electoral.

42 BAREIRO, Line y TORRES, Isabel. Igualdad para una democracia incluyente. IIDH, San José, 2009.

43 Ídem. 


\section{Conclusiones: el Estado mutante}

Los cambios se han vuelto acelerados no sólo en el reconocimiento de derechos, sino también en la búsqueda de reorganización de los Estados nacionales, en procesos simultáneos de descentralización y de integración regional que conllevan la cesión de parte de la soberanía a sistemas de protección de derechos humanos. No obstante, aunque pareciera que en la actual organización estatal, concebida como sistemas de privilegios y no de poblaciones que sean sujetos efectivos de derecho, no puede garantizarse la universalidad de derechos ya consagrados en los ordenamientos jurídicos.

Las mutaciones del Estado son parte de un proceso que apenas ha comenzado y que aún no se sabe a dónde conducirán las continuas y sucesivas reformas, en circunstancias que se ha modificado el mapa político con la inclusión al sistema político del protagonismo de sectores históricamente excluidos. No obstante, los mayores problemas de gobernabilidad democrática no parecieran estar vinculados a demandas de derechos, sino al mantenimiento de privilegios. 
